\title{
Uma poça d'água sublime. Representações da vertigem feminina
}

\author{
A sublime puddle. Representations of feminine vertigo \\ Olga Donata GUERIZOLI KEMPINSKA * \\ Universidade Federal Fluminense (UFF)
}

RESUMO: Tomando como ponto de partida a controvérsia teórica acerca das articulações estéticas e éticas entre kitsch, humor e sublime, este artigo debruça-se sobre sua encenação em alguns textos escritos por mulheres ao longo do século XX. O tema central é, nesse sentido, o da vertigem, que nas obras de Virginia Woolf, Maria Pawlikowska-Jasnorzewska, Wisława Szymborska e Clarice Lispector, se torna o momento-chave da representação da subjetividade feminina. Envolvido em vivências intensas expressas pela vertigem, o sujeito feminino surge em um primeiro momento como excepcional. No entanto, em virtude da presença do kitsch e do humor, a experiência do sublime, tradicionalmente codificada como relacionada a aventuras heroicas masculinas, vê-se subvertida. O sujeito feminino mostra-se então como falsamente excepcional e, graças a essa revelação, abre-se a possibilidade de um distanciamento crítico, a partir do qual o feminino surge como coisificado e infantilizado, ou seja, submetido à representação de cunho masculino.

PALAVRAS-CHAVE: Gênero. Kitsch. Sublime. Humor. Estética.

ABSTRACT: Taking as its starting point the discussion on the aesthetical and ethical articulations of kitsch, sublime and humor, this paper shows its mise-en-scène in several texts written by women during the $20^{\text {th }}$ Century. The main theme is vertigo, which, in works by Virginia Woolf, Maria Pawlikowska-Jasnorzewska, Wisława Szymborska and Clarice Lispector, corresponds to a key-point in the representation of feminine subjectivity. At a first moment, the feminine subject, involved in an intense experience expressed by vertigo, seems exceptional. However, the presence of kitsch and humor quickly leads to the subversion of the sublime, traditionally related to the masculine heroic adventure. The feminine subject, therefore, reveals itself as falsely exceptional and this revelation creates a critical distance, which transforms the feminine into an objectified and infantilized subject, subjected to a masculine perspective.

KEYWORDS: Gender. Kitsch. Sublime. Humor. Aesthetics.

\footnotetext{
* Doutora pela Universidade Federal Fluminense, Instituto de Letras, Departamento de Ciências da Linguagem, Niterói, Rio de Janeiro. E-mail: olgagkem@gmail.com
} 
"Hoje, quando a consciência dos dominados começa a coincidir com a tendência inteira da sociedade, dissolve-se a tensão entre cultura e kitsch", afirma Theodor Adorno (2008, p. 144). De origem alemã, a noção de kitsch, hoje em dia amplamente utilizada em diversas línguas, tanto como substantivo, quanto como adjetivo, remete a uma articulação necessária entre estética, ética e política. Defensor convicto dessa articulação e, ao mesmo tempo, o mais impiedoso crítico do kitsch, Adorno notou não apenas a incorporação da barbárie à cultura no âmbito da indústria cultural, mas também a transformação do "feminino" em kitsch. De fato, a respeito da questão feminina Adorno escrevia em 1945: "Na admissão das mulheres em todo tipo de atividades vigiadas esconde-se a perenidade de sua desumanização" (ADORNO, 2008, p. 88). Trata-se aqui antes de mais nada da assimilação pelas mulheres do ideal do feminino propagado pela indústria cultural, pois "de modo complacente e sem impulso opositor elas espelham a dominação e se identificam com ela" (ADORNO, 2008, p. 88). Resulta dessa situação, segundo o filósofo, uma perversa dinâmica de círculo vicioso, pois os defeitos com os quais as mulheres pagam pela acomodação à falta de liberdade, "em primeiro lugar a tolice neurótica", infelizmente apenas "contribuem para a permanência das condições" (ADORNO, 2008, p. 88).

Chamou minha atenção a surpreendente recorrência nas reflexões de Adorno sobre os temas do kitsch e da questão feminina. O filósofo está longe de passar por um feminista, tendo inclusive sido alvo de ataques das feministas alemãs nos anos 60 . Mesmo assim, pareceu-me instigante a maneira como o autor de Minima Moralia aproxima, ou até mesmo conjuga, os temas do feminino e do kitsch. Com efeito, associado à mentira e à incorporação da barbárie à cultura, o kitsch, enquanto uma forma de dominação assimilada pelas dominadas, chega, aos olhos de Adorno, a subjugar o feminino e a perpetrar a falta de autonomia das mulheres. Acrescenta-se ainda a essa crítica adorniana do kitsch uma condenação virulenta do humor, que é para o filósofo mais um sinónimo da barbárie:

$\mathrm{Na}$ falsa sociedade, o riso atacou - como uma doença - a felicidade, arrastando-a para a indigna totalidade dessa sociedade. Rir-se de alguma coisa é sempre ridicularizar, e a vida que, segundo Bergson, rompe com o riso a consolidação dos costumes, é na verdade a vida que irrompe barbaramente, a autoafirmação que ousa festejar numa ocasião social sua liberação do escrúpulo. Um grupo de pessoas a rir é uma paródia da humanidade. (ADORNO, 1985, p. 132) 
Dito de forma mais sintetizada, "dispensa a prova aquele que tem do seu lado o riso" (ADORNO, 2008, p. 206). Interpretando o humor, o riso e a ironia como consequências de um nefasto consenso gregário, Adorno associa essas práticas à completa falta de espírito crítico e ao escárnio agressivo, unilateral e de fortes componentes sádicas. Nesse mesmo sentido, nas considerações adornianas acerca da história da sátira, o satírico se torna sobretudo um apanágio de uma malícia herdada da "herança totalitária" (ADORNO, 2008, p. 207). O filósofo, dessa maneira, nega ao cômico em todas as suas formas qualquer potencial reflexivo e crítico.

No entanto, são justamente diversas formas do cômico que, como veremos, ao suscitarem o efeito humorístico, se revelam muitas vezes subversivas na encenação da subjetividade feminina. Em diversos textos escritos por mulheres ao longo do século $\mathrm{XX}$, a autoironia, o riso de si e o humor autorreflexivo, longe de serem afirmações unilaterais da identidade própria, permitem, ao contrário, estabelecer justamente uma percepção crítica da identidade feminina forjada pelos dominantes. Com efeito, a aproximação crítica entre o kitsch, a cultura e o humor encontrou nos anos 70 uma interlocutora instigante na poeta polonesa Wisława Szymborska. ${ }^{1}$ Desafiando a condenação violenta feita por Adorno, Szymborska insistiu sobretudo na proximidade necessária entre o kitsch e as grandes obras. Em uma de suas resenhas, dedicada em particular às ambivalências do livro barato e popular, a poeta afirmou que "entre uma obra-prima e o kitsch existe uma relação forte, vital aliás para ambos. Uma época na qual o kitsch fosse efetivamente abolido, não teria chance de produzir uma obra-prima" (SZYMBORSKA, 1981, p. 85). Foi ainda Szymborska que frisou a proximidade entre o kitsch e o humor, atribuindo a sua combinação paradoxal um valor positivo: "O kitsch, quanto pior tanto melhor, ou seja, mais engraçado" (SZYMBORSKA, 1981, p. 85).

Praticamente na mesma época no Brasil, em contraponto à associação adorniana entre o kitsch e a mentira, Clarice Lispector procurou enxergar no mau gosto um potencial de verdade: “Ah, a vontade que tenho de ceder ao mau gosto. Em quê? Ora, o campo é ilimitado, simplesmente ilimitado", exclama a autora em uma de suas crônicas. Tendo expresso sem pudor sua atração, Lispector acrescenta ainda: "A tentação é

\footnotetext{
${ }^{1}$ Wisława Szymborska (1923-2012) é uma poeta polonesa que ganhou o Prêmio Nobel de Literatura em 1996. Apesar do teor filosófico de seus textos, desafiou a ideia de uma poesia hermética e reservada a poucos. Subvertendo também a visão da poesia feminina dedicada à efusão emocional, Szymborska praticou sobretudo uma sutil ironia.
} 
grande, pois a linha divisória é quase invisível entre o mau gosto e a verdade" (LISPECTOR, 1999b, p. 188). Além dessa afirmação existencial, em algumas narrativas lispectorianas surge, como uma proposta poética e estética, uma curiosa economia do excesso. Como ainda veremos, a mesma velocidade da passagem imediata entre extremos, que pode ser resumida na fórmula "tudo por nada" e que transcreve momentos existenciais particularmente intensos da subjetividade feminina, é também articuladora da experiência do kitsch.

É à luz dessa controvérsia a respeito do kitsch, de sua relação com o humor e de seu potencial estético subversivo, que chamou minha atenção a encenação da vertigem em diversas obras escritas por mulheres no século XX. A mais conhecida é aquela tematizada em Mrs Dalloway, de Virginia Woolf. Trata-se de um "obscuro temor de 'suspense' ou interrupção" (BROWER, 1990, p. 69) do fluxo da vida, experimentado pela protagonista como uma recorrente tontura. Realizada como uma queda suicida por Septimus, o duplo da protagonista, essa vertigem articulava e ritmava, com efeito, o todo da vida de Clarissa que "sempre tinha a sensação de que era perigoso, perigosíssimo viver mesmo que fosse um único dia" (WOOLF, 2013, p. 15). Tornada ambivalente, a iminência da queda fatal chega por vezes no livro de Woolf a ser confundida com o entusiasmo de um mergulho: "e muitas vezes sentia, quando parava hesitante por um momento na soleira de sua sala de visitas, uma ansiedade deliciosa, tal como se deteria um mergulhador antes de saltar enquanto o mar se sombreia e se ilumina sob ele" (WOOLF, 2013, p. 39). Notemos de passagem que, na medida em que se vê associado à vertigem, o motivo da queda iminente se revela também como um desenvolvimento da temática considerada ainda no século XIX como tipicamente feminina, a do desmaio. Enquanto uma expressão extrema, o desmaio é visto pelas teorias fenomenológicas da emoção como uma "conduta" relacionada sobretudo à fuga (SARTRE, 2008, p. 34-35).

A mesma vertigem ambivalente que articula poeticamente a experiência da Mrs. Dalloway pode ser encontrada no breve poema da polonesa Maria PawlikowskaJasnorzewska, ${ }^{2}$ escrito em 1926, ou seja, apenas dois anos antes da narrativa de Woolf:

\footnotetext{
${ }^{2}$ Maria Pawlikowska-Jasnorzewska (1891-1945), poeta conhecida como a Safo polonesa, duas vezes divorciada, transformou seu sobrenome composto pelos nomes do segundo e do terceiro marido, um oficial da aviação, no principal nome da poesia erótica polonesa.
} 
Vejo você em peles envolta por completo,

hesitando perante uma pequena poça,

com um cachorrinho chinês sob o braço, um guarda-chuva e uma rosa...

E como vai dar esse passo para o perpétuo?

(PAWLIKOWSKA-JASNORZEWSKA, 2013, p. 114)

Ao encenar, não sem um ligeiro humor que maravilhosamente aproveita a forma breve do poema, o pavor perante uma poça d'água, não seria "La Précieuse", de Pawlikowska-Jasnorzewska mais uma imagem ambivalente de um mergulho sublime na vida e/ou na morte? Trazendo ecos intertextuais da Passante Baudelairiana, essa configuração do excesso não nos traz ecos daquele obscuro "pavor de entrar na experiência de viver a vida" (BROWER, 1990, p. 69), que articulava tanto o ritmo da vida de Clarissa quanto a narrativa Mrs Dalloway? Mas aqui, graças à tonalidade levemente humorística, ressaltada sobretudo pelo contraste entre o tamanho da poça e o peso da decoração carregada pela mulher - peso ritmicamente enfatizado pelo comprimento excessivo do terceiro verso que lista seus elementos -, a constatação da iminência do naufrágio descamba no ridículo. De fato, o naufrágio potencial da Précieuse tem lugar não em um oceano em tempestade kantiano, um dos palcos prediletos do sublime masculino, mas numa poça d'água - cotidiana, restrita, transitória e suja. E é justamente a cena desse naufrágio irrisório que abre um caminho interessante para a reflexão sobre a experiência do feminino enquanto envolvido em uma estética híbrida de kitsch, humor e sublime.

Quase na mesma época, entre 1929 e 1937, Cecília Meireles compõe em sua coletânea Viagem um epigrama que em vigorosos tetrassílabos ironicamente opõe a expansividade da travessia à estreiteza transitória. Lançando mão da forma tradicionalmente breve e engenhosa do epigrama, a poeta traça uma curiosa oposição entre duas raças. Uma de suas interpretações permite enxergar aqui uma tensão entre o masculino e o feminino:

\footnotetext{
A tua raça de aventura quis ter a terra, o céu, o mar.

Na minha, há uma delícia obscura Em não querer, em não ganhar...

A tua raça quer partir, Guerrear, sofrer, vencer, voltar.

A minha, não quer ir nem vir. A minha raça quer passar. (MEIRELES, 1972, p. 67)
} 
O poema empreende uma encenação vigorosa do contraponto entre a amplitude do desejo da conquista dos mares e o desejo de "passar". É o surgimento desse último verbo em um estranho contrapeso semântico na sequência sonora de três rimas precedentes - "mar - ganhar - voltar - passar" -, que se revela particularmente eloquente no contexto da presente discussão. É, de fato, nessa configuração sonora que parece concentrar-se o potencial irônico do poema, aparentemente enunciado como uma afirmação. "Passar" remete, assim, a uma transitoriedade sem desejo, aventura, nem glória, a um destino feito de pequenos, insignificantes e, mesmo assim, inseguros e hesitantes passos.

Foi sob o signo de uma "metafísica suscitada pela vista de uma poça d'água" (HARTWIG, 2004, p. 104) que, não sem malícia, a poeta polonesa Julia Hartwig ${ }^{3}$ aproximou recentemente "La Précieuse" (1926) e o poema "Poça de água" (2002), de Wisława Szymborska:

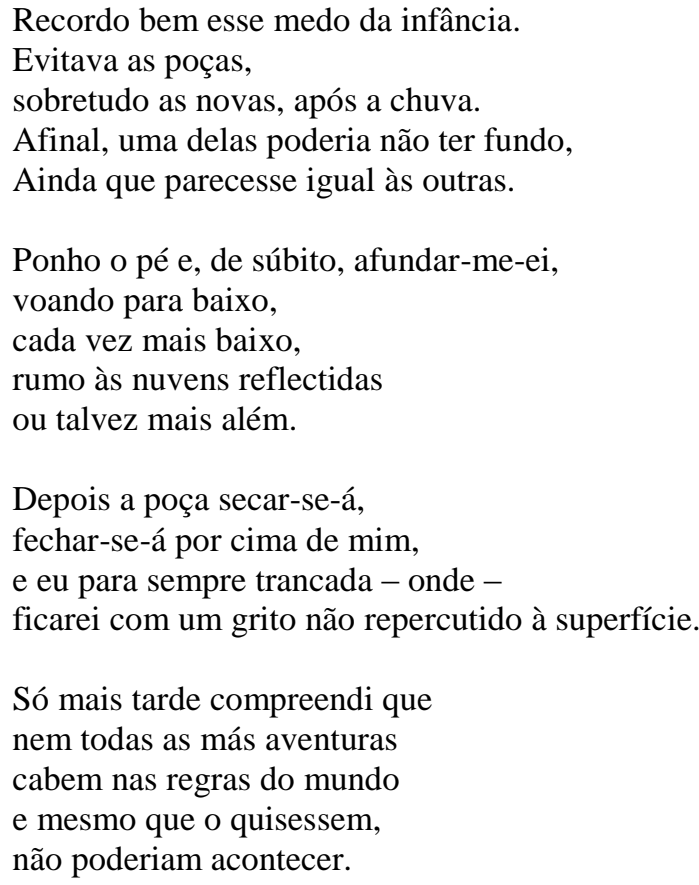

No poema de Szymborska não há mais dúvidas quanto ao potencial sublime da experiência da poça d'água. Ao retomar do sublime romântico a "transavaliação antinômica da verticalidade" (WEISKEL, 1994, p. 44), a poeta encena uma

\footnotetext{
${ }^{3}$ Julia Hartwig (1921-) é uma poeta, ensaísta e tradutora polonesa. Sua produção mais recente é um exemplo interessante e evocativo do "estilo tardio".
} 
reversibilidade entre o baixo do abismo e o alto do céu. Ao mesmo tempo, Szymborska faz do pavor metafisico suscitado pela poça d'água um medo meramente infantil, um conto de criança, uma história de alguma forma ultrapassada e exorcizada pela passagem do tempo. É verdade que o "eu-menina" que emerge do passado toma por um momento o lugar do "eu-adulto" atual. De fato, alguns teóricos entreveram no sublime uma experiência relacionada à imaturidade e deslocada, assim, para uma temporalidade ultrapassada pela idade madura. No poema de Szymborska, não sem intrigantes ecos da fantástica queda da Alice de Lewis Carroll, o medo metafísico suscitado pela poça d'água evita sua expansão ilimitada e seu efeito de adesão plena ao ser ele mesmo ridicularizado, tratado como um pesadelo bobo, uma fantasia desvairada.

Ao leitor brasileiro essas experiências de vertigens femininas talvez lembrem alguns dos momentos mais intensos descritos em certos textos de Clarice Lispector. "A fuga", texto escrito em 1940, traz, por exemplo, uma experiência de queda reiteradamente vivenciada no cotidiano de doze anos de casamento: "Eu comia caindo, dormia caindo, vivia caindo. Vou procurar um lugar onde pôr os pés...” (LISPECTOR, 1999a, p. 73). Ao sair de casa, a protagonista sente uma intensa vertigem na beira do mar:

Ficou um momento pensando se aquele trecho teria fundo, porque tornava-se impossível adivinhar: as águas escuras, sombrias, tanto poderiam estar a centímetros da areia quanto esconder o infinito. Resolveu tentar de novo aquela brincadeira, agora que estava livre. Bastava olhar demoradamente para dentro d'água e pensar que aquele mundo não tinha fim. Era como se estivesse se afogando e nunca encontrasse o fundo do mar com os pés. (LISPECTOR, 1999a, p. 72)

A vertigem relacionada ao pressentimento da abertura de um abismo sem fundo e de uma queda iminente surge aqui, paradoxalmente, como ao mesmo tempo opressora e libertadora. Atrelada a um conto antigo, ou seja, recolocada em um registro infantil, a queda libertadora ironicamente corresponde a únicos breves momentos de liberdade ilusória (a mulher voltará para casa no fim do dia):

\footnotetext{
A história de não encontrar o fundo do mar era antiga, vinha desde pequena. No capítulo da força da gravidade, na escola primária, inventara um homem com uma doença engraçada. Com ele a força da gravidade não pegava... Então ele caía para fora da terra, e ficava caindo sempre, porque ela não sabia lhe dar um destino. (LISPECTOR, 1999a, p. 72)
} 
Algo dessa vertigem feminina perante o mundo exterior deixa-se apreender também na breve crônica de 1952 intitulada "Um dia cheio": "Foi por isso que a mulher, depois de se sentar no bonde e de lançar uma tranquila vista de proprietária pelos bancos, engoliu um grito: ao seu lado, na mão de um homem gordo, estava aquilo que parecia um rato inquieto e que na verdade era um vivíssimo saguim" (LISPECTOR, 2012, p. 84-85). Como se o encontro com o animal ainda não tivesse sido o perigo suficientemente dramático na travessia feminina de bonde, em breve o carro há de ser quase virado por um enorme caminhão.

Mas a mais conhecida das passagens que indiretamente encenam uma queda iminente está no famoso "Perdoando Deus". Diferentemente dos seus precedentes, esse texto, escrito em 1970, já é fortemente marcado por uma tonalidade impura, tingindo-se de fortes nuances humorísticas:

\begin{abstract}
Tive então um sentimento de que nunca ouvi falar. Por puro carinho, eu me senti a mãe de Deus, que era a Terra, o mundo. Por puro carinho, mesmo, sem nenhuma prepotência ou glória, sem o menor senso de superioridade ou igualdade, eu era por carinho a mãe do que existe. Soube também que se tudo isso "fosse mesmo" o que eu sentia - e não possivelmente um equívoco de sentimento - que Deus sem nenhum orgulho e nenhuma pequenez se deixaria acarinhar, e sem nenhum compromisso comigo. Ser-Lhe-ia aceitável a intimidade com que eu fazia carinho. O sentimento era novo para mim, mas muito certo, e não ocorrera antes apenas porque não tinha podido ser. Sei que se ama ao que é Deus. Com amor grave, amor solene, respeito, medo e reverência. Mas nunca tinham me falado de carinho maternal por Ele. E assim como meu carinho por um filho não o reduz, até o alarga, assim ser mãe do mundo era o meu amor apenas livre. $\mathrm{E}$ foi então quando quase pisei num enorme rato morto. (LISPECTOR, 2009, p. 41-42)
\end{abstract}

A experiência sublime da proximidade do infinito divino é no texto lispectoriano brutalmente interrompida por uma experiência de quase pisar em um enorme rato morto. O crescimento do discurso prolixo do coração pleno esbarra na constatação sucinta de um acidente cotidiano, de modo que o sentimento quase místico topa contra a sujeira abjeta. O céu cai no chão, pois o sublime e o abjeto se entrechocam.

A vertigem frequentemente experimentada pela subjetividade feminina em contato com o mundo urbano que ultrapassa a esfera doméstica, encenada em textos de Woolf, Pawlikowska-Jasnorzewska, Szymborska e Lispector, remete, com efeito, a uma certa experiência do sublime. Nos textos citados, a mulher parece ora enfrentar um enorme perigo, ora entrar em contato com o infinito. A tentativa da descrição da vertigem que surge desses confrontos pode, de fato, trazer ecos dos mais diversos 
teóricos do sublime. Trata-se de algo que "ultrapassa todo padrão de medida dos sentidos" (KANT, 2002, p. 96); de uma exasperação daquele prazer relativo e ambivalente que é conhecido como "deleite" (BURKE, 1993, p. 45); de uma "peculiar agilidade para se movimentar entre dois polos" (HERTZ, 1994, p. 39); de um salto que é medido pela "largura do mundo" (LONGINO, 2005, p. 79); ou até de um "anseio por algo que talvez nunca tenha estado lá" (MOST, 2001, p. 194). Mais recentemente, Nuno Ramos descreveu essa experiência como uma vertigem formal:

\footnotetext{
Uma ou duas dimensões não são suficientes para nos deixar seguros diante do objeto a nossa frente. Precisamos das três. Se não pudermos controlar nenhuma (diante do oceano, por exemplo), o amorfo, disforme, monstruoso, ganha o contorno invertido do sublime. (RAMOS, 2011, p. 43).
}

À luz dessa constatação, seria interessante perguntarmo-nos qual dimensão falta nas aventuras da subjetividade feminina encenadas na literatura do século XX. Escritos a partir dos anos 20, época da conquista dos direitos eleitorais pelas mulheres no Reino Unido (plenamente em 1928), na Polônia (1918) e no Brasil (1932), muitos textos literários até hoje subvertem as delimitações da estética tradicional, revestindo-se de características de uma estética mista que combina o kitsch, o humor e o sublime.

Pois apesar de não desprovida de traços do amorfo, a vertigem experimentada pelo sujeito feminino rapidamente se revela como exagerada, e surge, então, sugerido no próprio texto, o tema de um engano, de um erro de cálculo. O perigo não é a travessia de um oceano em tempestade, mas apenas passagem de uma rua; o abismo insondável é mormente uma poça rasa; na calçada, que não é uma rota celestial, tem por vezes um ou outro bicho morto. Nos textos citados, o impulso de expansão emocional e imaginária vê-se repentinamente frustrado, revelando seu caráter impuro de um sublime contrafeito. Assim, o confronto entre o sujeito feminino e o destino extremo transformase de repente em um mero contraste entre o ilimitado e o estreito, entre o infinito e o banal. O perigo não era o de morrer, mas apenas o de molhar ou sujar sapatos; no máximo, o de tropeçar e levar um tombo. O "tudo" se torna repentinamente um "nada", uma besteira, uma sujeira ou esquisitice qualquer. É justamente esse contraste que, graças à mediação do humor, expõe o surgimento do kitsch em meio à experiência do sublime.

Em uma de suas narrativas, Lispector chega a descrever uma singular economia de "tudo por nada": "É possível também que já então meu tema de vida fosse a 
irrazoável esperança, e que eu já tivesse iniciado a minha grande obstinação: eu daria tudo o que era meu por nada, mas queria que tudo me fosse dado por nada" (LISPECTOR, 1999b, p. 264). De fato, a capacidade de atribuir repentinamente uma enorme carga emocional ("tudo") a algo insignificante, a um nada, ao envolver uma exagerada oscilação do sentimento entre dois polos da experiência, parece cotejar também a experiência do kitsch, que consiste em uma adesão emocional plena. Sendo um grande defensor da nuance e da resistência enquanto articuladoras da dúvida e da negatividade na relação com a representação, Adorno criticava na experiência do kitsch justamente a plenitude exacerbada da adesão. Sem dúvida, a própria categoria do kitsch mostra-se interessante e produtiva não como uma coleção de objetos, estilos ou características formais objetivas, mas enquanto uma atitude estética, um tipo de "relação que o ser mantém com as coisas" (MOLES, 1998, p. 11). Seu caráter mais marcante reside justamente na conduta emocional do sujeito comparável a um círculo fechado, pois uma vez que muito de seu vigor provém da dinâmica autocomplacente, a experiência do kitsch tem também uma forte tendência à viciosa autoalimentação. Nesse sentido, a fenomenologia do kitsch remete à circularidade fortemente narcisista da experiência emocional, baseada em uma susceptibilidade emocional (Rührseligkeit) “que se emociona consigo mesma" (GIESZ, 2007, p. 238).

No entanto, o surgimento e, sobretudo, o crescimento expansivo da "corrupção alarmante" (RIOUT, 2004, p. 673) da experiência por meio do kitsch encontram-se em muitos textos escritos por mulheres subvertidos pela presença do humor. Assim, envolvido em momentos de fulgor que exacerbam a experiência subjetiva, o "eu" feminino surge em um primeiro momento como excepcional, particularmente apto ao sentimento intenso, a uma vertigem emocional. No entanto, rapidamente esse caráter sublime das imagens de abismos, travessias e naufrágios, culturalmente codificadas como aventuras heroicas masculinas, vê-se questionado através da subversão por meio do kitsch e do humor. O "eu" feminino, falsamente excepcional, que, ao invés de enfrentar abismos insondáveis e distâncias entre mundos, por pouco não pisa em uma poça ou em um rato morto, adquire uma duplicidade e, com esta, uma representação mais passível de um distanciamento crítico. Os perigos ridículos do cotidiano, através dos quais se confirma o lado infantil ou decorativo atribuído à mulher, permitem reconhecer, com um humor particularmente amargo, a mentira quanto à 
"excepcionalidade". Justamente através de seus matizes humorísticos e do kitsch, o "eu" feminino surge como fungível, coisificado, submetido à representação de cunho masculino que o remete à infância, à fragilidade e à hipersensibilidade doentia.

Termino essa reflexão com a confissão de Lispector acerca de uma tentativa fracassada de se encontrar, em 1968, uma perspectiva válida para relatar acontecimentos atuais do ponto de vista "feminino":

\begin{abstract}
Uma vez me ofereceram fazer uma crônica de comentários sobre acontecimentos, só que essa crônica seria feita para mulheres e a estas dirigida. Terminou dando em nada a proposta, felizmente. Digo felizmente porque desconfio de que a coluna ia era descambar para assuntos estritamente femininos, na extensão em que feminino é geralmente tomado pelos homens e mesmo pelas próprias humildes mulheres: como se mulher fizesse parte de uma comunidade fechada, à parte, e de certo modo segregada. Mas minha desconfiança vinha de lembrar-me do dia em que uma moça veio me entrevistar sobre literatura, e, juro que não sei como, terminamos conversando sobre a melhor marca do delineador líquido para maquilagem dos olhos. (LISPECTOR, 1999b, p. 108-109)
\end{abstract}

Apesar da falta de sucesso da empreitada jornalística, percebe-se nessa pequena passagem uma evocativa transformação da desconfiança perante a visão do feminino forjada pelo olhar masculino em uma autodesconfiança frente à adesão própria às representações vigentes. Lispector faz do humor autorreflexivo seu importante aliado nos esforços de operar sutis transições de pontos de vistas e abrir, dessa forma, caminhos a enfoques não apenas críticos, mas sobretudo autocríticos. De forma semelhante, a tonalidade esteticamente cambaleante de muitos textos escritos por mulheres ao longo do século XX pode ser interpretada como uma manifestação da urgência de se inventar um lugar a partir do qual falar, lugar que possa ser chamando de feminino sem significar o feminino construído pelo olhar (e em oposição ao) masculino.

\title{
REFERÊNCIAS
}

ADORNO, T. W. Minima moralia. Tradução de G. Cohn. Rio de Janeiro: Beco do Azogue, 2008.

ADORNO, T. W.; HORKHEIMER, M. Dialética do esclarecimento. Tradução de G. A. de Almeida. Rio de Janeiro: Jorge Zahar, 1985.

BROWER, R. A. Something Central Which Permeated. In: BLOOM, H. (Org.).

Clarissa Dalloway. New York: Chelasea House, 1990. p. 67-77.

BURKE, E. Uma investigação filosófica sobre a origem de nossas ideias do sublime e do belo. Tradução de E. A. Dobránszky. Campinas: UNICAMP, 1993. 
GIESZ, L. Phänomenologie des Kitsches. In: DETTMAR, U; KÜPPER, T. (Orgs.).

Kitsch: Texte und Theorien. Stuttgart: Reclam, 2007. p. 237-240.

HARTWIG, J. Zwierzenia i błyski. Varsóvia: Sic!, 2004.

HERTZ, N. O fim da linha: ensaios sobre a psicanálise e o sublime. Tradução de J.

Castañon Guimarães. Rio de Janeiro: Imago, 1994.

KANT, I. Crítica da faculdade do juízo. Tradução de V. Rohden e A. Marques. Rio de Janeiro: Forense, 2002.

LISPECTOR, C. A bela e a fera. Rio de Janeiro: Rocco, 1999a.

. Clarice na cabeceira: jornalismo. Rio de Janeiro: Rocco, 2012.

. A descoberta do mundo. Rio de Janeiro: Rocco, 1999b.

. Felicidade clandestina: contos. Rio de Janeiro: Rocco, 2009.

LONGINO ou DIONÍSIO. Do sublime. In: Poética clássica. Tradução de J.

Bruna. São Paulo: Cultrix, 2005. p. 69-114.

MEIRELES, C. Flor de poemas. Rio de Janeiro: Aguilar, 1972.

MOLES, A. O kitsch. Tradução de S. Miceli. São Paulo: Perspectiva, 1998.

MOST, G. W. Depois do sublime: estágios na trajetória de uma emoção. In:

ROSENFIELD, D. L. (Org.). Ética e estética. Rio de Janeiro: Jorge Zahar, 2001. p. 177196.

PAWLIKOWSKA-JASNORZEWSKA, M. A amante do piloto. Tradução de O.

Kempinska. Revista Literária em Tradução, Florianópolis, v. 7, p. 98-126, 2013.

RAMOS, N. Cujo. São Paulo: Editora 34, 2011.

RIOUT, D. Kitsch. In: CASSIN, B. (Org.). Vocabulaire européen des philosophies.

Paris: Seuil\&Le Robert, 2004. p. 672-673.

SARTRE, J. P. Esboço para uma teoria das emoções. Tradução de P. Neves. Porto Alegre: L\&PM, 2008.

SZYMBORSKA, W. Instante. Tradução de E. Milewska e S. Neves. Lisboa: Relógio d'Água, 2006.

Lektury nadobowiązowe. Cracóvia: Wydawnictwo Literackie, 1981.

WEISKEL, T. O sublime romântico: estudos sobre a estrutura e psicologia da transcendência. Tradução de P. Flores da Cunha. Rio de Janeiro: Imago, 1994.

WOOLF, V. Mrs Dalloway. Tradução de D. Bottmann. Porto Alegre: L\&PM, 2013. 